\title{
VIRUS-LIGAND INTERACTIONS OF OC43 CORONAVIRUS WITH CELL MEMBRANES
}

\author{
Arlene R. Collins \\ Department of Microbiology \\ State Univ. of NY at Buffalo \\ Buffalo, NY 14214
}

\begin{abstract}
The binding of human coronavirus OC43 to human rhabdomyosarcoma cells which are highly susceptible to infection was studied by a solid phase virus binding assay and a receptor blockade assay. It was observed that whole virions and S(spike) bound to a $90 \mathrm{kD}$ glycoprotein of RD cells even after treatment of the substrate with neuraminidase or $0.1 \mathrm{M}$ $\mathrm{NaOH}$. A second receptor of $45 \mathrm{kD}$ also bound virus and was identified as HLA class I antigen. Antibody to both receptors reduced the virus yield in a receptor blockade assay. Sera from four patients with multiple sclerosis contained receptor blocking activity which correlated with antibodies to HLA. No receptor blocking antibodies to the $90 \mathrm{kD}$ RD cell protein were found in human sera.
\end{abstract}

\section{INTRODUCTION}

Human coronaviruses are the cause of acute respiratory illness and have been associated with enteric disease in man. As such, their target cells are likely to be the epithelial cells lining the respiratory and enteric tract. Attachment of virus to specific receptors on the cell surface is a major determinant of virus tropism and pathogenesis ${ }^{1}$. Recently, aminopeptidase- $\mathrm{N}$ was identified as a cell receptor for the human coronavirus $229 \mathrm{E} 2$. A cell receptor for OC43 coronavirus has not been identified. The pathogenesis of human coronaviruses is also of concern in association with the autoimmune disease, multiple sclerosis (MS). Recently, interest in this association has been rekindled by the report of Murray et al. ${ }^{3}$ in which probing MS and control brain with probes specific for human, murine, porcine and bovine coronaviruses by in situ hybridization resulted in the detection of coronavirus RNA in 12 or 22 MS samples, five of which reacted with the OC43 probe. Also, the coronavirus strains isolated from MS brain have been shown to cause focal demyelinating lesions in monkeys ${ }^{4}$. A study of virus-ligand interactions of OC43 with human rhabdomyosarcoma (RD) cells, which are highly susceptible to infection, was undertaken to identify possible cell receptors and to assess interactions of the virions with host cell molecules. 


\section{METHODS}

\section{Viruses and Cells}

Human coronaviruses OC43 and 229E were plaque purified in MRC-5, human diploid lung cells (Viro Med, Minnetonka, MN 55343). Stock virus was maintained by passage in MRD-5 cells. Human rhabdomyosarcoma (RD) cells were obtained from R. Crowell, Hanneman Medical College, Philadelphia, PA. Monkey kidney, CV-l cells were obtained from R. Hughes, RPCI, Buffalo, NY. For plaque assays virus suspensions were diluted in EMEM and duplicate volumes of $0.2 \mathrm{ml}$ were allowed to adsorb to MRC-5 cells in 24 well trays (Costar, Cambridge, MA) for $1 \mathrm{~h}$ at $37^{\circ} \mathrm{C}$. The monolayers were then overlayed with $0.5 \mathrm{ml}$ of $0.5 \%$ agarose with EMEM plus $0.2 \%$ serum. Cultures were stained with neutral red, and plaques were counted after 4 days at $33^{\circ} \mathrm{C}$. The titer was determined as the average number of plaques per dilution times the dilution.

\section{Antiserum Production}

The procedure of Knudsen 5 was followed. Briefly, the $90 \mathrm{~K}$ RD protein was separated by PAGE electrophoresis and eluted from the gel by transfer to nitrocellulose paper. The protein-bearing nitrocellulose was solubilized with dimethyl sulfoxide and used as an immunogen in rabbits. An equal volume of Freund's adjuvant, either complete (first injection) or incomplete (subsequent injections) was added to the mixture which was then injected subcutaneously in four sites in the rabbit. A total of four injections was given at two week intervals. Antisera were tested by a Western blot assay and in the receptor blocking assay.

\section{Monoclonal Antibodies}

Monoclonal anti-human HLA class I-ABC, clone w6/321, mouse IgG2a was obtained as ascites fluid $(10 \mathrm{mg} / \mathrm{ml})$ from C-six Diagnostics, Inc., Mequon, WI 53092. Monoclonal antibovine coronavirus antibody to $110 / 120$ peplomer, clone Bio-09, was purchased from Biosoft, AMAC, Inc., Westbrook, ME 04092.

\section{Human Sera}

Sera from multiple sclerosis patients (ages 16-53) were collected at the W.C. Baird Multiple Sclerosis Centre, Dr. Lawrence Jacobs, Director, Buffalo, NY. Sera from normal subjects who tested CMV positive (cytomegalovirus antibody positive) were obtained from the Regional Red Cross Blood Centre.

\section{Virus-Immunoblot Assay}

Growth and purification of virus: HCV-OC43 was propagated in RD cells. Supernatant virus was harvested after $4-5$ days incubation at $33^{\circ} \mathrm{C}$, clarified by low speed centrifugation $(1000 \mathrm{x} \mathrm{g}, 10 \mathrm{~min}$.) and sedimented by ultra-centrifugation at $100,000 \mathrm{x} \mathrm{g}$ for $4 \mathrm{~h}$ in a Beckman T35 rotor. The pellet was resuspended at $100 \mathrm{x}$ concentration in TMEN buffer (50 $\mathrm{mM}$ Tris-maleate, $1 \mathrm{mM}$ EDTA, $100 \mathrm{mM} \mathrm{NaCl} \mathrm{pH} \mathrm{6.5).} \mathrm{For} \mathrm{virus} \mathrm{purification,} \mathrm{concentrated}$ virus was layered onto a sucrose gradient (20-60\% w/w in TMEN) and centrifuged in an SW41 rotor at $60,000 \times \mathrm{g}$ for $4 \mathrm{~h}$. The virus band (about $3 \mathrm{~cm}$ from the bottom) was collected, diluted in phosphate buffered saline (PBS, $0.1 \mathrm{M}, \mathrm{pH} 7.2$ ) and sedimented under the same conditions. The pellet was resuspended in PBS and stored at $-70^{\circ} \mathrm{C}$. Spike and HE peplomers of the virions were obtained by disrupting the virions in $1 \%$ n-octylglucopyranoside and separation on a $10-30 \% \mathrm{w} / \mathrm{w}$ sucrose gradient centrifuged at $105,000 \mathrm{x} \mathrm{g}$ for $18 \mathrm{~h}^{6}$.

Substrate. Cells grown in T75 flasks (Costar, Cambridge MA 02139) were washed twice with rinse buffer (20 mM Tris- $\mathrm{HCl}, \mathrm{pH} 9.0,137 \mathrm{mM} \mathrm{NaCl}, 1 \mathrm{mM} \mathrm{CaCl} 2$ and $0.5 \mathrm{mM}$ $\mathrm{MgCl} 2$ ) and solubilized on ice for $20 \mathrm{~min}$. in $1 \mathrm{ml}$ ice cold lysis buffer (rinse buffer with $1 \%$ $\mathrm{v} / \mathrm{v}$ NP40, $10 \% \mathrm{v} / \mathrm{v}$ glycerol, $1 \% \mathrm{v} / \mathrm{v}$ aprotinin). Insoluble cell debris was pelleted at $1000 \mathrm{x} \mathrm{g}$ for $10 \mathrm{~min}$. and the clarified cell lysates were stored at $-70^{\circ} \mathrm{C}$. 
Preparation of Solid Phase Substrate. Purified virus in 2 x sample buffer, $\mathrm{L}+\mathrm{H}$ molecular weight markers (BioRad, Richmond CA 94804) in 2 x sample buffer were boiled 5 min and loaded along with cell lysates in lysis buffer (30-45 $\mu \mathrm{g}$ protein per lane) onto $10 \%$ SDS gels, $0.75 \mathrm{~mm}$ thickness. Proteins were separated at $10 \mathrm{~mA}$ per slab for $1-2 \mathrm{~h}$ and immediately transferred onto Immobilon-P membranes (Millipore, Bedford, MA 01730) for 25-30 min in transfer buffer (0.1 M Tris, $0.129 \mathrm{M}$ glycine $\mathrm{pH} 8.4,20 \%$ methanol, $0.1 \%$ SDS) at $100 \mathrm{~mA}$ constant current. Membranes containing transferred proteins were soaked in $5 \%$ bovine serum albumin in TBS buffer $(0.01 \mathrm{M}$ Tris- $\mathrm{HCl} \mathrm{pH} 7.5,0.15 \mathrm{M} \mathrm{NaCl})$ at $37^{\circ} \mathrm{C}$ for 30 min and washed three times in TBS with $0.1 \%$ bovine serum albumin (TBS-BSA).

Solid Phase Binding. The interaction of OC43 with cell membrane proteins was performed as follows: OC43 virus (512 HAU) in $5 \mathrm{ml}$ TBS-BSA was incubated with solid phase substrate at $25^{\circ} \mathrm{C}$ for $1 \mathrm{~h}$ with gentle shaking. To detect bound virus the membranes were washed three times with TBS-BSA and then incubated with a 1:200 dilution of rabbit anti-OC43 polyclonal antibody (prepared by immunization with gradient purified virus from infected suckling mouse brain) for $1 \mathrm{~h}$ at $25^{\circ} \mathrm{C}$. Virus bound antibody was visualized by incubation with horseradish peroxidase-conjugated goat anti-rabbit IgG 1:1000 dilution (BioRad) and developed in TBS buffer containing $0.5 \mathrm{mg} / \mathrm{ml}$ 4-chloro-1-naphthol and $0.03 \%$ $\mathrm{H}_{2} \mathrm{O}_{2}$.

\section{Receptor Blocking Assay}

RD cells grown in 24 well culture trays ( $1.4 \times 10^{5}$ cells per well), were incubated for $1 \mathrm{~h}$ at $37^{\circ} \mathrm{C}$ with $0.5 \mathrm{ml}$ of EMEM containing heat inactivated antibody diluted twofold beginning at 1:100. The antibody was removed and the cells were infected with virus at a multiplicity of 1 in $0.2 \mathrm{ml}$ inoculum for $1 \mathrm{~h}$ at $38^{\circ} \mathrm{C}$. After washing the monolayer twice to remove unbound virus, the cells were incubated for $24 \mathrm{~h}$ at $37^{\circ} \mathrm{C}$ in EMEM containing the antibody. Cells were then scraped into the medium and frozen at $-70^{\circ} \mathrm{C}$ for titration by plaque assay. Receptor blockade was expressed as percent inhibition of virus yield and was determined by calculating the difference in virus yield between the virus titer in the presence of each antibody dilution and the virus titer of the untreated control. When pre-immune rabbit serum was tested in the receptor blocking assay, $50 \%$ inhibition was given by the 1:50 dilution but $<10 \%$ inhibition at the twofold greater dilution.

\section{RESULTS}

Multiple RD cell proteins bound OC43 virus in a virus immunoblot assay comparing RD cell membranes and CV-l cell membranes (Figure 1). In the RD membrane preparation, the virus-binding bands were observed at approximately $90 \mathrm{kD}, 45 \mathrm{kD}$ and $36 \mathrm{kD}$. Some binding activity is visible with the CV-l membrane preparations. This was also seen in the control substrate when incubated with rabbit antibody alone. It was further observed that treatment of the substrate with neuraminidase (from C. perfringens, 10 units in $0.1 \mathrm{M}$ acetate, $\mathrm{pH} 6.0$ ) or sodium hydroxide $(0.1 \mathrm{M})$ for 30 min did not remove the virus binding activity of the $90 \mathrm{kD}$ RD protein.

In order to characterize the virus binding proteins of RD cells, antibodies that would specifically block each virus-protein interaction were sought. For the $90 \mathrm{kD}$ RD cell protein, a rabbit antibody was raised by immunization with the protein band excised from nitrocellulose. For the $45 \mathrm{kD}$ RD cell protein, a monoclonal antibody, w6/32, to HLA class I antigen was found to be reactive. The $36 \mathrm{kD}$ RD cell protein is still uncharacterized. Binding of virus to specific RD cell proteins was repeatable with gradient purified virus.

\section{Identification of the virus binding-RD cell proteins by specific antibodies}

RD cell proteins were separated on SDS-PAGE gels and eluted from the gel by transfer to Immobilon membranes. After blocking non-specific sites on the membrane by incubation with $5 \%$ bovine serum albumin, the membranes were reacted with test antibodies at 1:100, 1:200 and 1:400 dilution along with pre-immune rabbit serum. One lane of RD cell protein substrate 
was reacted with the second antibody (goat anti-rabbit or goat anti-mouse conjugated to horseradish peroxidase, 1:1000 dilution) alone. The rabbit antibody raised to the $90 \mathrm{~K} \mathrm{RD}$ protein bound to a single protein as shown by the band in the 90,000 molecular weight region of the gel (Figure 2a). Pre-immune rabbit serum at 1:100 dilution was negative. The w6/32, anti human HLA class I antibody bound to a single RD cell protein shown by the band at 45,000 , the approximate molecular weight of the HLA class I heavy chain. No bands were visible in the CV-l cell control lane (Figure $2 b$ ).

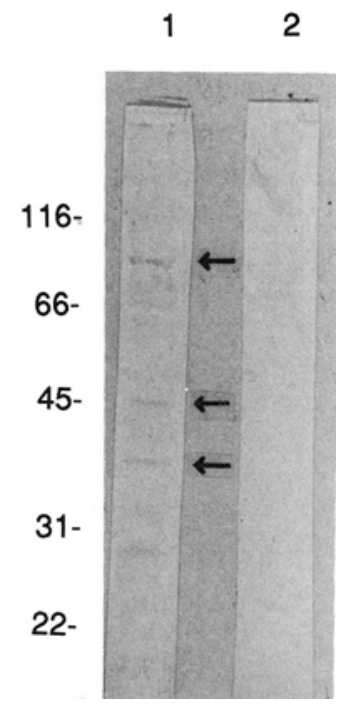

Figure 1. Binding of OC43 to RD cell proteins. Solubilized RD cell proteins after SDS-PAGE were transferred to Immobilon (Millipore) and reacted with OC43 virions (lane 1) or without virions (lane 2). Virus binding was detected by rabbit anti-OC43 antibody, goat anti-rabbit HRP conjugate and the reaction was developed with 4-chloro-1-naphthol. The virus binding bands are at $90 \mathrm{kD}, 45 \mathrm{kD}$ and $36 \mathrm{kD}$ as indicated by the arrows.

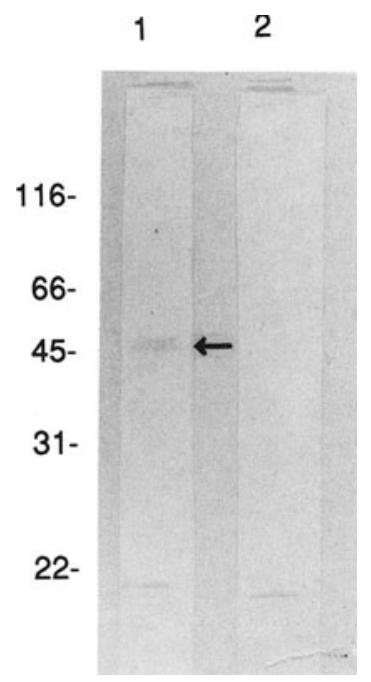

Figure 2. Binding of antibodies to $\mathrm{RD}$ cell receptor proteins. Solubilized cell proteins (lane $1 \mathrm{RD}$ cells, lane 2 CV-l cells), after SDS-PAGE, were transferred to Immobilon (Millipore) and reacted with (A) $90 \mathrm{kD}$ RD cell antibody or (B) monoclonal anti-HLA class I antibody $(10 \mu / \mathrm{ml})$. Binding of primary antibody was detected with goat anti-mouse or rabbit-HRP conjugate and the reaction was developed with 4-chloro-1-naphthol. The $90 \mathrm{kD}$ and $45 \mathrm{kD}$ bands are indicated by arrows. 


\section{Identification of multiple virus receptors by receptor blockade}

It was then important to identify those virus-binding reactions that could lead to infection of RD cells. Using RD cell monolayers as target cells, the ability of antibodies to $90 \mathrm{kD} \mathrm{RD}$, HLA class I (w6/32) and BCV 110/120 kD peplomer to block OC43 virus infection when present in the supernatant medium was compared. Serial dilutions of antibodies were incubated with the RD cells for $1 \mathrm{~h}$ prior to infection and for $24 \mathrm{~h}$ after infection and the effect on virus yield was determined by comparing virus plaque titers in samples with antibody to the virus titer of an untreated control (Figure 3). Rabbit antibody to the $90 \mathrm{k}$ RD protein blocked the production of infectious virus in these experiments. The highest concentration (1:100) gave incomplete protection from virus infection showing a $96 \%$ reduction in the total yield. The preimmune rabbit serum gave less than $10 \%$ inhibition at this concentration. w6/32 monoclonal antibody was very effective in blocking infectious virus production. At 1:400 dilution of antibody, $25 \mu \mathrm{g} / \mathrm{ml}$, less than $10^{2}$ plaque forming units of virus were synthesized. Monoclonal antibody to the BCV $110 / 120 \mathrm{kD}$ peplomer gave a $40 \%$ reduction in OC43 virus yield at the 1:100 dilution.

Using the $229 \mathrm{E}$ virus, a human coronavirus belonging to another group, w6/32 antibody reduced the virus yield by less than $10 \%$ at the 1:100 dilution, indicating that the HLA class I antigen was not a receptor for the $229 \mathrm{E}$ virus.

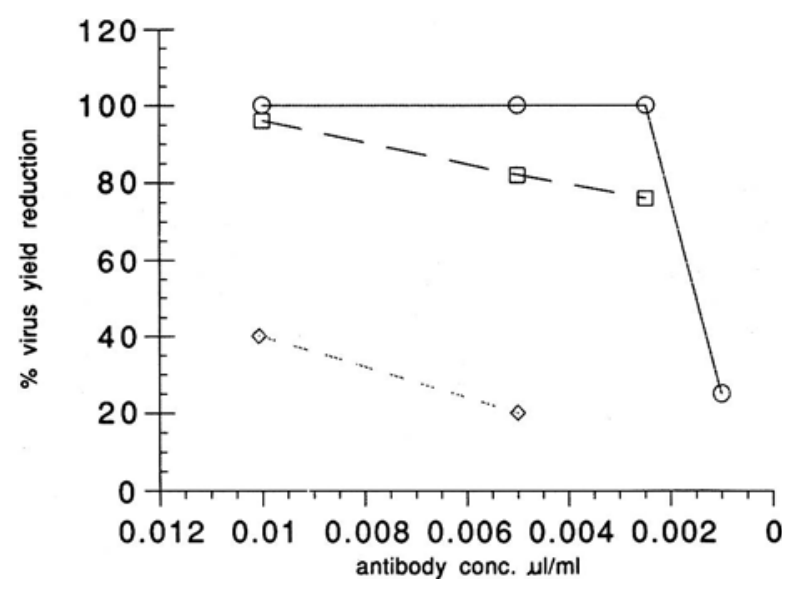

Figure 3. Inhibition of OC43 virus replication by anti-receptor antibody. RD cell monolayers were treated for $1 \mathrm{~h}$ with various dilutions of antibody, infected with $\mathrm{OC} 43$ virus at a multiplicity of 1 for $1 \mathrm{~h}$ at $37^{\circ} \mathrm{C}$, washed twice and reincubated for $24 \mathrm{~h}$ at $33^{\circ} \mathrm{C}$ with medium containing antibody. The total virus yields were then determined by plaque assay and the \% yield reduction due to antibody was calculated by comparison to the virus controls (without antibody). Open circle--anti HLA, open square--anti $90 \mathrm{kD} \mathrm{RD,} 0$-anti BCV 110/120 kD protein.

\section{Correlation of cell receptor antibody with blocking activity in Human sera}

In order to study the possibility that human sera contain antibodies to $90 \mathrm{kD} R D$ cell protein, twenty human sera (10 MS, $10 \mathrm{CMV}$ ) were screened for antibodies which bound to the protein in the solid phase assay. Six out of 20 adult human sera contained antibodies which recognized $90 \mathrm{kD}$ RD. When these sera were tested in the receptor blockade assay, four of the six sera were able to reduce virus yield by $30-100 \%$ when present during virus replication in vitro. Another five of the 20 sera (indicated by the open circles in Figure 4a) inhibited virus 
replication but did not contain antibodies to $90 \mathrm{kD}$ RD. Similarly, the human sera were also tested for antibodies to the $45 \mathrm{kD}$ HLA class I antigen and correlation of the presence of these antibodies with inhibition of virus replication was examined (Figure 4b). Out of eight human sera with antibodies which bound to $45 \mathrm{kD}$ HLA class I antigen, four inhibited virus replication by $50-120 \%$. All four sera came from multiple sclerosis patients. The other four sera with HLA class I antibodies which did not inhibit virus replication, came from CMV positive blood donors.

a)

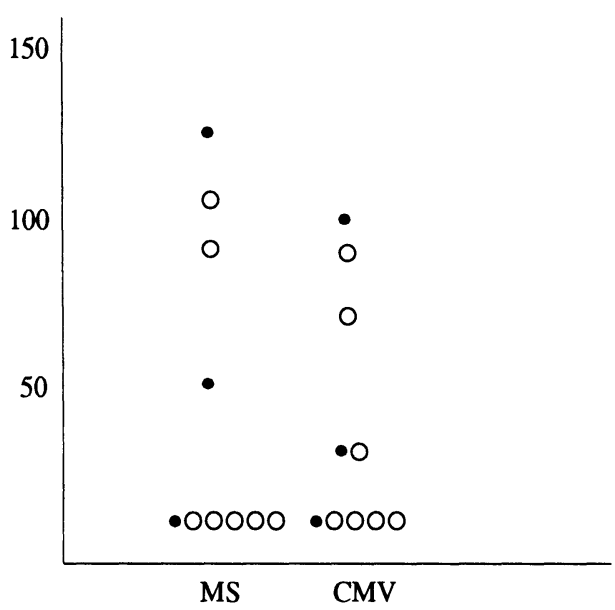

b)

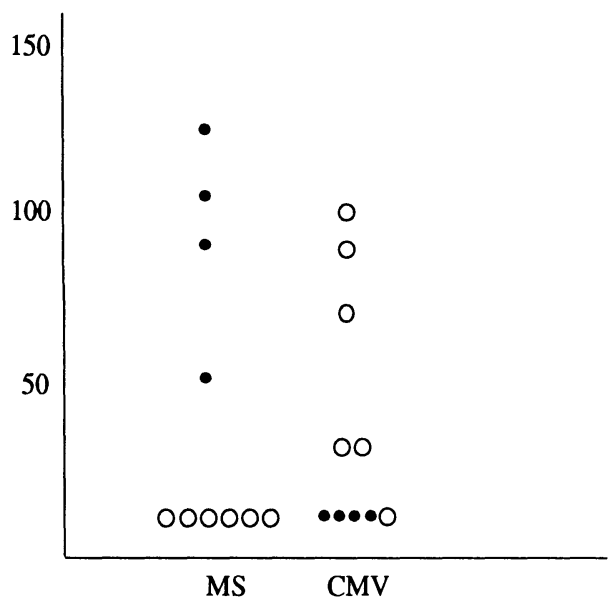

Figure 4. Association of antibodies to virus binding proteins with receptor blocking activity in human sera. $\mathrm{MS}$, sera from multiple sclerosis patients; CMV sera from normal blood donors who are CMV antibody positive. Inhibition of virus yield (percent) by sera (diluted 1:200) with (solid circles) and without (empty circles) antibodies to the $90 \mathrm{kD} \mathrm{RD}$ cell protein are shown in (A) and antibodies to HLA class I antigen are shown in (B).

\section{DISCUSSION}

The preliminary results presented here indicate that multiple receptors for OC43 coronavirus are found on RD cells. At least three bands (at $90 \mathrm{kD}, 45 \mathrm{kD}$ and $36 \mathrm{kD}$ molecular weight) were seen by virus-immunoblotting of RD cell proteins. While membrane proteins were thought to be the ligand in this assay, the possibility that cytoplasmic proteins bound to the virus was not excluded. Virus binding to intracellular proteins would also be of interest since such interactions could lead to alterations in cell function. Another method was employed to identify those proteins likely to be on the cell surface.

The receptor blockade test employed antibodies of known specificity to identify the cell proteins with receptor activity. The ability of receptor antibody to block infection is indirect evidence of receptor activity. Introduction of the receptor molecule into previously negative cells would be direct proof. However, blocking infectivity by antibody gives preliminary evidence of receptor activity. Previous studies with human Coxsackie B3, rhinovirus 14 and murine coronavirus A59 have shown that antibodies to a specific receptor reduced viral replication and modulated disease $1,6,7$.

The experiments reported here indicate that two receptor specificities, $90 \mathrm{kD} \mathrm{RD}$ and HLA class I are involved in OC43 infection of RD cells. Rabbit antibody raised to the $90 \mathrm{kD}$ $\mathrm{RD}$ cell protein incompletely blocked virus infection. The reason may be that the antigen used 
for immunization lacked conformational domains present in the native molecule or that more than one receptor is involved. HLA class I antigen appears to be an essential component of the virus attachment complex since monoclonal antibody w6/32 completely blocked infectivity. Previously, monoclonal antibody w6/32 was used to show that measles virus-specific $T$ cell clones were HLA class II restricted and not HLA class I ${ }^{8}$. HLA class I is a member of the immunoglobulin gene superfamily which includes carcinoembryonic antigen, the receptor for mouse hepatitis virus (MHV). The MHV receptor plays an important role in the pathogenesis of MHV infections. SJL/J mice which lack a functional virus receptor, are resistant to MHV infection and develop chronic demyelination ${ }^{9}$. MHV and OC43 belong to the same serogroup. It would be reasonable to expect that the two viruses could use receptors which are structurally similar.

In the experiments to screen human sera for anti-receptor antibody, a correlation between the presence of antibodies to HLA class I and inhibition of virus replication was observed for four sera, all from MS patients. Another four sera with HLA class I antibodies did not inhibit virus replication. These were from CMV positive blood donors. CMV is known to express a glycoprotein similar to HLA with 13 potential glycosylation sites in contrast to only one-three in HLA molecules 10 . This glycoprotein may stimulate the antibody response which was observed. HLA A, B and C specific antibodies are normally found in multiparous women and in recipients of multiple blood transfusions. This pilot study suggests that an environmental exposure in some MS cases may produce HLA specific antibodies that block coronavirus receptors.

The involvement of more than one cell protein as receptor is of considerable interest since the process of virus attachment and penetration for this virus may be quite complex. The envelope of OC43 virus contains two types of surface peplomers: a spike protein which recognizes 9-(0-acetylated sialic acid as a receptor determinant and a hemagglutinin-esterase which is a less efficient hemagglutinin and an esterase capable of cleaving the 9-0-acetyl bond which comprises the receptor determinant 11 . Virus binding the $90 \mathrm{kD}$ RD protein is esterase resistant suggesting that this interaction is likely to be irreversible. Utilization of HLA antigen as a virus receptor would involve a mechanism different from antigen presentation which is the normal function of HLA in infected cells. The relatively large mass of individual virions and the mobility of the HLA antigens in the membrane suggests that multiple HLA receptor sites may be occupied by the virus and may undergo conformational changes making available other receptors embedded further in the plasma membrane. Further studies are underway to identify these complexes.

\section{REFERENCES}

1. F.G. Hayden, J.M. Gwaltney and R.J. Colonno, Antiviral Res. 9:233-247 (1988).

2. C.L. Yeager, R.A. Ashmun, R.K. Williams, C.B. Cardellichio, L.H.Shapiro, A.T. Look and K.V. Holmes, Nature 357:420-422 (1992).

3. S.R. Weiss, Virology 126:669-677 (1983)

4. R.S. Murray, B. Brown, D. Brian and G.F. Cabirac, Ann. Neurol. 31:525-533 (1992).

5. K. Kundsen, Anal. Biochem. 147:285-288 (1985).

6. A.H. Weller, K. Simpson, M. Herzum, N. van Houten and S.A. Huber, J.Immunol. 143:1843-1850 (1989).

7. A.L. Smith, C.B. Cardellichio, D.F. Winograd, M.S. deSouza, S.W.Barthold and K.V. Holmes, J. Infect. Dis. 163:879-882 (1991).

8. S. Jacobson, T. Nepom, J.R. Richert and H.F. McFarland, J. Exp. Med. 161:263-268 (1985).

9. R. Williams, G-S. Jiang and K.V. Holmes, Proc. Natl. Acad. Sci. USA 88:5533-5536 (1991).

10. S. Beck and B.G. Barrell, Nature 331:269-272 (1988).

11. B. Schultze, H-J. Gross, R. Bossmer and G. Herrler, J. Virol. 65:6232-6237 (1991). 